\title{
sciendo
}

\author{
Current Issues in Pharmacy and Medical Sciences \\ Formerly ANNALES UNIVERSITATIS MARIAE CURIE-SKLODOWSKA, SECTIO DDD, PHARMACIA

\section{Biochemical aspects of $\mathrm{KB}-28$ compound on physically loaded study subjects}

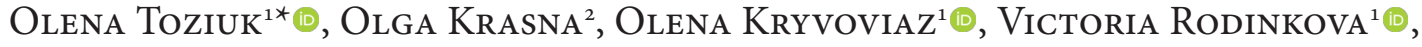

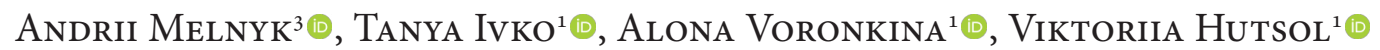

\author{
${ }^{1}$ Pharmacy Department, National Pirogov Memorial Medical University, Vinnytsya, Pirogov 56, Vinnytsia, Ukraine \\ ${ }^{2}$ General Pharmacy Department, Odessa National Medical University, Valikhovsky Lane 2, Odessa, Ukraine \\ ${ }^{3}$ Department of Biological and General Chemistry, National Pirogov Memorial Medical University, Vinnytsya, Pirogov 56, Vinnytsia, \\ Ukraine
}

\section{ARTICLE INFO \\ Received 27 December 2018 \\ Accepted 03 April 2019 \\ Keywords: \\ acute lymphoblastic leukemia, physical endurance, carbohydrate metabolism, lipid metabolism, \\ 2-ethylthiobenzimidazole hydrobromide, \\ sodium 2-(tetrazolo[1,5-c] quinazoline-5-ylthio)acetate.}

\begin{abstract}
In previous studies of actoprotective activity of 5-R-thio-tetrazolo[1,5]quinazoline derivatives in normal and complicated experimental conditions, sodium 2-(tetrazolo [1,5-c] quinazoline-5-ylthio)acetate (KB-28) was found to be the leader of the experiment. The objective of the current study was to characterize the effects of KB-28 compounds on carbohydrate and lipid exchange indices under the conditions of physical load as a possible mechanism of actoprotective effect. In the course of the experiment, the indices of carbohydrate and lipid exchange in the muscle, blood and liver of animal models were determined following a 15-day physical load course. In doing so, glucose, glycogen and total lipid concentrations were assessed. The KB-28 compound was administered daily at levels determined during the course of regular physical load normalized metabolic processes in rats. The results were then compared to a control which received intraperitoneally the equivolume $0.9 \%$ sodium chloride solution. The phenomenon of actoprotection consisted in enhancing concentrations of glycogen in skeletal muscles and liver. Compared to the control figures, this increase was $28.8 \%$ and $25.0 \%$, accordingly. Moreover, the course of KB-28 caused a statistically significant reduction (by $32.1 \%$ ) of the total serum lipid concentration in the animals under physical load. The effect may be a sign of the ability of this substance to utilize active lipolysis for improvement of the skeletal muscle performance. Having analyzed the results obtained, we can draw a conclusion that influencing the biochemical processes in the study models is one of the mechanisms of the KB-28 actoprotective effect.
\end{abstract}

\section{INTRODUCTION}

A large number of adverse natural, anthropogenic, informational and psychological factors affect everyday life [1]. This process is accompanied by a significant growth of morbidity, and medical science puts such pathological conditions together under the general term "civilizational diseases". The term covers cardiovascular, gastrointestinal, psychiatric and other affections [2,3].

One of the manifestations of these diseases is decreasing physical endurance [4]. In this regard, improvement of the body's resistance to counter adverse factors and the maintenance of normal levels of work performance are considered to be urgent tasks. This problem is possible to solve by

\footnotetext{
* Corresponding author

e-mail: olena.tozyuk@gmail.com
}

using pharmacological agents. Medicines from the group of actoprotectors are considered promising in this regard $[5,6]$. These substances are designed to maintain high motor activity and physical endurance under extreme conditions. These are characterized by non-exhausting effects that aid in economizing energy consumption. Today, this group of medicines is represented by 2-ethylthiobenzimidazole hydrobromide (2-EBHB) and nothing more. However, the medicine has a number of side-effects (gastralgia, facial hyperemia, excessive psychostimulatory activity), which limit its widespread use $[5,6]$. This same feature determines the necessity of developing highly effective substances with actoprotective effect, suitable for creation of new medicines with the above-mentioned effect on the basis thereof [7-9]. 
Sodium 2-(tetrazolo[1,5-c]quinazoline-5-ylthio)acetate (KB-28 compound) was found to be a leader in the previous studies of actoprotective activity of new derivatives of 5-R-thio-tetrazolo[1,5-c]quinazoline under normal and augmented experimental conditions $[10,11]$. Derivatives of the above class of substances were synthesized by the staff of the Department of Organic and Bioorganic Chemistry of the Zaporizhzhia State Medical University [12]. The structural formula of KB-28 compound is as follows:<smiles>OSc1nc2ccccc2c2nnnn12</smiles>

Figure 1. The structural formula of KB-28 compound

In research, KB-28 was able to improve physical endurance of rat models under normal and augmented experimental loads. The above activity was manifested by an increase of the swimming length under normo-, hyper- and hypothermia settings $[10,11]$. The same manifestation was seen in rotated rod and treadmill run experiments $[13,14]$. The ability of KB-28 compound to increase physical endurance of a body has preconditioned the prospectivity of further studies of suitability of the compound for creating new actoprotective medicines.

It is known that disorders of metabolic processes play a central role in fatigue pathogenesis. The positive effect of 2-EBHB on the physical functioning of a body is actualized through activating influences on the gluconeogenesis process $[5,6]$. To establish possible mechanisms of the actoprotective effect of sodium 2-(tetrazolo[1,5-c]quinazoline-5-ylthio) acetate, it was necessary to determine its influence on metabolic processes in physically loaded rat models.

\section{AIM}

To characterize the influence of KB-28 compounds on carbohydrate and lipid metabolism in physically loaded animal models as a possible mechanism of actoprotective action.

\section{MATERIALS AND METHODS}

\section{Animal groups and substances}

The experiments were performed on 56 white rats of the Wistar strain, obtained from the vivarium of the National Pirogov Memorial Medical University, Vinnytsya. The duration of quarantine was 2 weeks. The animals were kept on a standard diet with free access to water and feed, with a natural day and night regimen. The animals were fed a semi-synthetic starch-casein diet with a balanced content of all macro- and micronutrients. Individually marked animals, selected after quarantine, were placed into groups of 14 animals each with homogenous body weight ( $\pm 15 \%)$. All experiments were carried out according to the National Institute of Health Guidelines for the care and use of laboratory animals and the European Council Directive on 24
November 1986 for Care and Use of Laboratory Animals (86/609/EEC), and were approved by the the bioethics commission of the National Pirogov Memorial Medical University, Vinnytsya (Minutes No. 7 dated 24 April 2014). As a reference substance, we used actoprotector 2-ETBH.

The Rats were divided into 4 groups of 14 animals each: 1 - intact rats; 2 - rats subjected to training load without correction (trained control); 3 and 4 - rats, dosed $1.7 \mathrm{mg} / \mathrm{kg}$ of compound KB-28 and $32.0 \mathrm{mg} / \mathrm{kg}$ of reference substance 2-ETBH respectively on the background of regular physical load. The substances, dissolved in isotonic sodium chloride solution, were administered to animals intraperitoneally $60 \mathrm{~min}$ before treadmill training. These substances were used in mean effective doses $\left(\mathrm{ED}_{50}\right) . \mathrm{ED}_{50}$ were calculated graphically via the Litchfield-Wilcoxon method based on the results of the swimming test in the normothermia conditions [10]. The control group of rats received intraperitoneally the equivolume $0.9 \%$ sodium chloride solution.

\section{Research of physical endurance}

Rats from the 2-4 groups were loaded daily $5 \mathrm{~min}$ for 14 days in a treadmill at a speed of tape $28 \pm 1.0 \mathrm{~m} / \mathrm{min}$ and track angle $10^{\circ}$. Loading animals into a treadmill enables to adjust the intensity of work, and this regime is considered most appropriate for small laboratory animals [15]. In addition, such loads correspond to the high level of intensity of physical work, and it is performed by activating the aerobic-anaerobic energy path, which in this case was the most appropriate for assessment of metabolic changes in the test animals $[16,17]$.

On the 15th day of the experiment, the rats from 2-4 groups were loaded with running at a speed of $42 \mathrm{~m} / \mathrm{min}$ and slope angle $10^{\circ}$. In the first phase of the experiment (half the rats from 2-4 groups, 7 subjects from each group), we investigated their physical capacity against duration of the race until complete exhaustion, confirmed by no reaction to stimulation with electrical charges $(40 \mathrm{~V})$ at the starting line of the treadmill [15]. The remaining 7 animals from groups 2-4 ( $2^{\text {nd }}$ phase of the experiment $)$ were loaded with treadmill running under the same conditions for $10 \mathrm{~min}$. Samples of biological material for the study of energy metabolism indicators were taken 3-5 min after exercise from all the rats from the $2^{\text {nd }}$ phase of experiment and from the intact rats (group 1).

\section{Biochemical researches}

Biological material (fragment of femoral muscle and the liver) was sampled after decapitation of animals under thiopental anesthesia. After the organs (skeletal muscles and liver) were collected, their perfusion was determined using a saline solution, they were then weighed and frozen in liquid nitrogen. Biochemical analysis was performed in the organ extract deproteinized with perchloric acid 1:3.25 $(0.6 \mathrm{M}$ solution of $\mathrm{HClO} 4)$ and neutralized with $5 \mathrm{M}$ solution of $\mathrm{K}_{2} \mathrm{CO}_{3}$. The level of blood lipids in the serum was determined after their acid hydrolysis, using the reaction with the vanillin-phosphoric reagent from the test kits produced by «PLIVA-Lachema Diagnostika» (Czech Republic).

The glucose concentration in the blood serum and homogenate of skeletal muscles was determined by way 
of the glucose oxidase method, using the "Glucose-F" kit (Phyllis-Diagnosis, Ukraine).

The amount of glycogen was assessed after the acid hydrolysis by the increase in the glucose level [18]. Here, $3 \mathrm{ml}$ of ethanol was added to $0.1 \mathrm{ml}$ of the deproteinized extract of skletal muscle and liver, the mixture was kept for 1 hour at $37^{\circ} \mathrm{C}$ and then centrifuged for 30 minutes at $1000 \mathrm{~g}$, the obtained precipitate was twice washed with ethanol. Acid hydrolysis was then performed with $4 \mathrm{M}$ solution of $\mathrm{H}_{2} \mathrm{SO}_{4}$ in a boiling water bath for 2 hours. Subsequently, the hydrolysate was cooled and then neutralized with $2 \mathrm{M} \mathrm{KOH}$ solution, the $\mathrm{pH}$ was stabilized with $0.1 \mathrm{M}$ tris-HCI buffer ( $\mathrm{pH}$ 7.6) and the increase in the glucose level was determined.

\section{Statistical Analysis}

We processed the digital data obtained from the study by way of the variation statistics technique, using IBM SPSS Statistic 22 software, Herein, we calculated mean value $M$, the arithmetic mean error $\mathrm{m}$, and t-Student's criterion for normal distribution, White nonparametric criterion - if the latter was not available, and Wilcoxon (paired samples) criterion - was also applied in order to determine changes in the trend within the group. The changes of parameters were considered significant at $\mathrm{p}<0.05$.

\section{RESULTS}

During the first experimental phase, the effect of daily training on the physical endurance of rats was assessed (Table 1). We found that the average running length in the group of trained control animals was $20.8 \mathrm{~min}$. The obtained data were in perfect agreement with the concept that trained individuals had a much higher endurance level than the untrained $[4,19]$.

Table 1: Effect of KB-28 compound and 2-ETBI on rat treadmill run length on Day 15 of training $(\mathrm{M} \pm \mathrm{m}, \mathrm{n}=7)$

\begin{tabular}{|l|c|c|}
\hline Experimental conditions & Running time (min.) & $\begin{array}{c}\text { Change compared } \\
\text { to control }(\%)\end{array}$ \\
\hline $\begin{array}{l}\text { Exercise }+0.9 \% \mathrm{NaCl} \\
\text { (trained control) }\end{array}$ & $20.8 \pm 3.2$ & - \\
\hline Exercise $+\mathrm{KB}-28$ & $39.2 \pm 4.2 *$ & +88.5 \\
\hline Exercise +2 -ETBI & $35.8 \pm 3.8^{*}$ & +72.1 \\
\hline
\end{tabular}

Note: * - statistically significant change compared to control, $p<0.05$; $\mathrm{n}$ - number of subjects in a group

Course administration of KB-28 in rats at daily training contributed to a significant increase of physical endurance. This was evidenced by the statistically important increase of running time compared to the control animals $(+88.5 \%)$. A similar trend was also noted in the administration of the reference actoprotector. The physical endurance of animals increased by $72.1 \%$ following administration of 2-EBHB. By expressiveness of actoprotective effect, KB-28 compound administered in a dose of $1.7 \mathrm{mg} / \mathrm{kg}$ was not inferior to 2 -EBHB in a dose of $32.0 \mathrm{mg} / \mathrm{kg}$.

The possible mechanism of actoprotective effect of KB-28 compound was studied during the $2^{\text {nd }}$ phase of the experiment. The results of the study of biochemical parameters of animals under conditions of daily physical load are presented in Table 2.
We found that daily treadmill training of rats brought about significant changes in metabolic processes on Day 15 of the experiment. This was manifested by a statistically significant reduction of glycogen content in skeletal muscle by a mean of $27 \%$. It should also be noted that concentration of glucose in the blood of rats from the group of trained control was enhanced compared to that in the intact animals $(+32.1 \%)$.

A statistically significant increase of total lipid concentration in the blood by $73 \%$ was also noted in the group of trained control.

Daily administration of KB-28 compound in parallel with regular exercise normalized metabolic processes in the rat models. The sign of this was the enhanced content of glycogen in skeletal muscles by $28.8 \%$, compared to the control. The glycogen level also grew by $22.4 \%$ following 2-EBHB administration (Table 2). A similar trend was observed in the study of liver glycogen concentration. The course administration of KB-28 and 2-EBHB caused the index to be boosted by 25.0 and $17.4 \%$, respectively. Along with this, glucose levels increased in the skeletal muscles. On KB-28 compound administration, this index demonstrated a statistically significant growth by $21 \%$; on 2 -EBHB administration, the index was enhanced by $23 \%$. At the same time, blood glucose concentration in animals influenced by the study substances decreased to some extent compared to the control, approaching the level of intact rats.

Course administration of the study substances also induced statistically significant decreases of serum total lipid concentration in the trained animals. Thus, administration of KB-28 and 2-EBHB brought about statistically significant decrease of total lipids, compared to control (32.1 and 27\%, respectively).

Table 2: Effect of KB-28 and 2-ETBI on biochemical processes in rats loaded with daily treadmill running $(\mathrm{M} \pm \mathrm{m}, \mathrm{n}=7)$

\begin{tabular}{|c|c|c|c|c|}
\hline \multirow[b]{2}{*}{ Indicators } & \multirow[b]{2}{*}{ Intact rats } & \multicolumn{3}{|c|}{ Post-training } \\
\hline & & \begin{tabular}{|c|}
$0.9 \% \mathrm{NaCl}$ \\
(trained control)
\end{tabular} & KB-28 & 2-ETBI \\
\hline \multicolumn{5}{|c|}{ Skeletal muscles } \\
\hline $\begin{array}{l}\text { Glycogen } \\
\text { (mg/g tissue) }\end{array}$ & $23.3 \pm 1.9$ & $\begin{array}{l}17.0 \pm 1.2 * \\
(-27.0 \%) \mathrm{i}\end{array}$ & $\begin{array}{l}21.9 \pm 2.1 \# \\
(+28.8 \%) k\end{array}$ & $\begin{array}{l}20.8 \pm 1.8 \\
(+22.4 \%) \mathrm{k}\end{array}$ \\
\hline $\begin{array}{l}\text { Glucose } \\
(\mathrm{mmol} / \mathrm{g} \\
\text { tissue) }\end{array}$ & $4.66 \pm 0.44$ & $\begin{array}{l}5.22 \pm 0.47 \\
(+12.0 \%) \mathrm{i}\end{array}$ & $\begin{array}{l}6.31 \pm 0.52 * \\
(+21.0 \%) \mathrm{k}\end{array}$ & $\begin{array}{l}6.42 \pm 0.61 * \\
(+23.0 \%) \mathrm{k}\end{array}$ \\
\hline \multicolumn{5}{|c|}{ Blood serum } \\
\hline $\begin{array}{l}\text { Glucose } \\
(\mathrm{mmol} / \mathrm{l})\end{array}$ & $4.76 \pm 0.35$ & \begin{tabular}{l|}
$6.29 \pm 0.67$ \\
$(+32.1 \%) \mathrm{i}$ \\
\end{tabular} & $\begin{array}{l}5.08 \pm 0.42 \\
(-19.2 \%) k\end{array}$ & $\begin{array}{l}5.14 \pm 0.51 \\
(-18.3 \%) k\end{array}$ \\
\hline $\begin{array}{l}\text { Total lipids } \\
(\mathrm{g} / \mathrm{l})\end{array}$ & $2.62 \pm 0.19$ & $\begin{array}{l}4.54 \pm 0.26 * \\
(+73.3 \%) \mathrm{i}\end{array}$ & $\begin{array}{c}3.08 \pm 0.28 \# \\
(-32.1 \%) \mathrm{k}\end{array}$ & $\begin{array}{c}3.32 \pm 0.31 \# \\
(-27.0 \%) \mathrm{k}\end{array}$ \\
\hline \multicolumn{5}{|c|}{ Homogenate of the liver } \\
\hline $\begin{array}{l}\text { Glycogen } \\
\text { (mg/g tissue) }\end{array}$ & $58.7 \pm 4.3$ & $\begin{array}{c}67.8 \pm 3.8 \\
(+15.5 \%) \mathrm{i}\end{array}$ & $\begin{array}{l}84.7 \pm 5.2 * \# \\
(+25.0 \%) \mathrm{k}\end{array}$ & $\begin{array}{c}79.6 \pm 4.6^{*} \\
(+17.4 \%) \mathrm{k}\end{array}$ \\
\hline
\end{tabular}

Note: $*$ - statistically significant change compared to intact group, $\mathrm{p}<0.05$; \# - statistically significant change compared to control group, $\mathrm{p}<0.05$; $\mathrm{i}$ - index trend compared to intact group; $\mathrm{k}$ - index trend compared to control group; $\mathrm{n}$ - number of subjects in a group

\section{DISCUSSION}

The statistically significant reduction of glycogen content in skeletal muscle shows evidence of depletion of carbohydrate energy reserves in the body of rats under dosed physical load without correction. In this case, the liver concentration of glycogen was maintained at a rather high level (Table 2). This trend confirmed the known fact of intensive 
consumption of own glycogen by muscles for maintaining physical activity $[4,20]$.

An increase in concentration of glucose in the blood of rats from the group of trained control may be a sign of intensified glycogenolysis in skeletal muscles. This process is a consequence of activation of the sympathoadrenal system under intense physical load [19].

A statistically significant increase of total lipid concentration in the blood could be considered as a sign of the mobilization of adipocytes and the use thereof as an additional source of energy by $\beta$-oxidation of free fatty acids [4]. It is known that lipid metabolism plays an important role in the aerobic energy supply for muscle activity, since it is much more energy-intensive than carbohydrate metabolism.

The growth of carbohydrate reserves of the body and prevention of hyperglycemia may be regarded as the activation of adaptation processes associated with administration of the studied substances within a period of physical load $[4,19]$.

The statistically significant decrease of serum total lipid concentration in the trained animals may be a sign of the ability of these substances to utilize active lipolysis for enhancement of skeletal muscle function. It is known that intensive free fatty acid oxidation contributes to preservation of carbohydrate reserves within the period of physical load [21].

The study results suggest that the KB-28 compound contributed to preservation of the carbohydrate reserves of the organism. Such reserves are required for maintaining the energy supply processes at an appropriate level. Moreover, carbohydrates play an important role in the antioxidant protection of the organism [2]. It is well known that intense physical activity causes oxidative stress in the body $[22,23]$. In previous studies, we found that $\mathrm{KB}-28$ compound demonstrated obvious antioxidant effect [13].

The actoprotective effect of KB-28 compound and 2-EBHB on animals loaded by a 10 minute treadmill running during 14 days was implemented by way of normalizing the disturbed metabolic processes. This manifested in growing levels of glucose and glycogen in the liver and muscles. Lipolysis also contributed to improvement of the physical performance. Having analyzed the results obtained, we can assume that influence on the biochemical processes of the organism is one of the mechanisms of actoprotective action of the KB-28 compound.

\section{CONCLUSION}

The results of the study suggest that course administration of KB-28 compound $(1.7 \mathrm{mg} / \mathrm{kg})$ upon the condition of regular physical load on rats results in a $88.5 \%$ increased performance in treadmill experiments. The effect is preconditioned by the ability of KB-28 to increase the level of glycogen in the muscles and the liver (by 28.8 and $25 \%$, accordingly), to improve the glucose uptake (a decrease of blood concentration and an increase of skeletal muscle concentration by 19.2 and $21 \%$, accordingly). The reduction of serum total lipid concentration by $32.1 \%$ suggests the activation of lipolysis. Thus, the actoprotective effect of KB-28 is enabled through normalization of disturbed metabolic processes.

\section{FINANCIAL SUPPORT AND SPONSORSHIP}

\section{Nil.}

\section{CONFLICT OF INTERESTS}

There are no conflicts of interest.

\section{ORCID iDs}

Olena Toziuk (Dhttps://orcid.org/0000-0002-8429-6624 Olena Kryvoviaz Dhttps://orcid.org/0000-0001-5441-1903 Victoria Rodinkova (Dhttps://orcid.org/0000-0003-0741-1104 Andrii Melnyk (Dhttps://orcid.org/0000-0003-1315-7958 Tanya Ivko Dhttps://orcid.org/0000-0003-2873-1473

Alona Voronkina Dhttps://orcid.org/0000-0003-2750-0884

Viktoriia Hutsol Dhttps://orcid.org/0000-0003-1477-2186

\section{REFERENCES}

1. Gratas-Delamarche A, Derbre F, Vincent S, Cillard J. Physical inactivity, insulin resistance, and the oxidative-inflammatory loop. Free Rad Res. 2014;1:93-108. https://doi.org/10.3109/10715762.201 3.847528

2. Nikolaidis MG, Kyparos A, Spanou C, Paschalis V, Theodorou AA, Vrabas IS. Redox biology of exercise: an integrative and comparative consideration of some overlooked issues. J Exp Biol. 2012;215(10):1615-25. https://doi.org10.1242/jeb.067470

3. Rauch HG, Schonbachler G, Noakes TD. Neural correlates of motor vigour and motor urgency during exercise. Sports Med. 2013;43:227241. https://doi.org10.1007/s40279-013-0025-1

4. Wilmor JH, Costill DI. Physiology of sport and exercise. Illinois: Human Kinetics; 2004:726

5. Lukyanchuk VD, Simonova IV. Actoprotectors: pharmacology and pharmacotherapy. Pharmacol Med Toxicol. 2015;2:14-26

6. Oliynyk S, Oh S. The Pharmacology of Actoprotectors: Practical Application for Improvement of Mental and Physical Performance. Biomols Ther. 2012;20(5):446-56. https://doi.org10.4062/ biomolther.2012.20.5.446

7. Kolomoets OS, Nosulenko IS, Voskoboynik OY, Berest GG, Kovalenko SI, Trzhetsinsky SD. Actoprotective activity of 6-monosubstituted 3-R-6,7-dihydro-2H-[1,2,4]triazino-[2,3-c]quinazoline-2ones. Curr Issues Pharm Med Sci Pract. 2016;3:59-66. https://doi. org10.14739/2409-2932.2016.3.77996

8. Kolomoets OS, Voskoboynik OY, Nosulenko IS, Kryvoshey OV, Avramenko AI, Berest GG. 3'-R-spiro[cycloalkyl-1(2), (hetaryl-3 (4), $6^{\prime}$-[1,2,4]triazino[2,3-c]quinazoline]-2'(7’H)-2-ones as a perspective class of compounds with actoprotective activity. Zaporozhye Med J. 2017;19:227-32. https://doi.org/10.14739/2310-1210. 2017.2.95748

9. Saienko A, Voloshchuk N, Toziuk O, Kryvoviaz O, Kryvoviaz S, Koval V. Assessment of MT-279 compound effect on physical endurance of rats under conditions of chronic hypokinesia. Current Issues in Pharmacy and Medical Sciences. 2017;3:134-7. https://doi. org/10.1515/cipms-2017-0024

10. Stepanjuk GI, Toziuk OYu, Kovalenko SI, Chornoivan NG, Antipenko LM, Antipenko OM, inventors; National Pirogov Memorial Medical University, Vinnytsya, assignee. 5-R-thiotetrazolo[1,5-c]quinazolines which increase the physical endurance. Ukraine Patent 79229. 2013 Apr 10; Bulleten 7

11. Toziuk O, Kryvoviaz O, Kryvoviaz S, Ivko T, Balicka O. Effect of 5-R-Thio-Tetrazolo[1,5-C]Quinazoline Derivatives on the Physical Performance in Different Types of Physical Exercise. Asian J Pharm. 2017;11(3)(Suppl):532-5. http://dx.doi.org/10.22377/ajp.v11i03.1455

12. Antypenko OM, Kovalenko SI, Karpenko OV. Synthesis and hydrolytic cleavage of tetrazolo[1,5-c]quinazolines. Synth Commun. 2016;46:551-5. http://doi.org/10.1080/00397911.2016.1156131

13. Toziuk O. Investigation of effect of sodium 2-(tetrazolquinazolin5-iltio)-acetate (compound KB-28) on the metabolic processes in organism during intensive exercise. ScienceRise: Pharmaceutical Science. 2016;4:60-4. https://doi.org/10.15587/2519-4852.2016.88010 
14. Toziuk O, Voloshchuk N, Germanyuk T, Kryvoviaz O, Kryvoviaz S, Ivko T et. al. Characteristics of 2-(tetrazol[1,5-c] quinazolin-5-ylthio) acetate effect on the level of adenine nucleotides in intense physical activity. International Journal of Green Pharmacy. 2017;4:276-80. http://doi.org/10.22377/ijgp.v10i04.1295

15. Contarteze RV, Manchado FB, Gobatto CA, De Mello MA. Stress biomarkers in rats submitted to swimming and treadmill running exercises. Comp Biochem Physiol A Mol Integr Physiol. 2008;151(3):415-22. http://doi.org/10.1016/j.cbpa.2007.03.005

16. Hubner-Wozniak I, Kosmol A, Blachnio D. Anaerobic capacity of upper and lower limbs muscles in combat sports contestants. J Combat Sports and Martial. 2011;2(2):91-4. http://doi.org/10.5604/ 20815735.1047140

17. Chamari K, Padulo J. 'Aerobic' and 'Anaerobic' terms used in exercise physiology: a critical terminology reflection. Sports Med Open. 2015;1(9):1-4. http://doi.org/10.1186/s40798-015-0012-1
18. Kits Van Heijningen AJ, Kemp A. Free and fixed glycogen in rat muscle. Biochem J. 1955;59:487-91

19. Selye H. 1974. Stress without Distress. Philadelphia: Lippincott.

20. Baker JS, McCormick MC, Robergs RA. Interaction among skeletal muscle metabolic energy systems during intense exercise. J Nutr Metab. 2010;Article ID 905612:2-13. http://dx.doi.org/ $10.1155 / 2010 / 905612$

21. Eizadi M, Nazem F, Zarifyan A, Eghdami A, Khorshidi D. The Effect of Chronic Intake of L-carnitine L-tartrate on Lipid Metabolism during Aerobic Exercise. J Kerman U Med Sci. 2010;17(2):113-20

22. Ji LL, Zhang Y. Antioxidant and anti-inflammatory effects of exercise: role of redox signaling. Free Rad Res. 2013;48(1):3-11. http:// doi.org/10.3109/ 10715762.2013.844341

23. Pingitore A, Lima G, Mastorci F, Quinones A, Iervasi G, Vassalle C. Exercise and oxidative stress: Potential effects of antioxidant dietary strategies in sports. Nutrition. 2015;31(7-8):916-22. http://doi.org/ 10.1016/j.nut.2015.02.005 